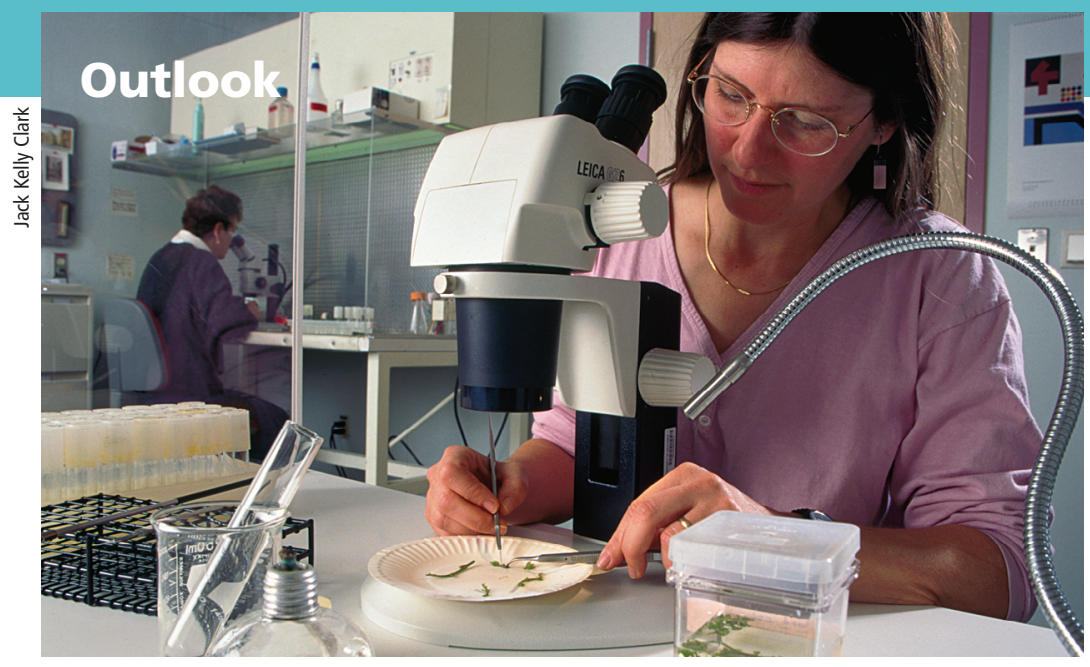

\title{
Sustained public investment needed for agricultural research
}

Ted Batkin, President, Citrus Research Board

Robert Curtis, Senior Manager, Almond Board of California

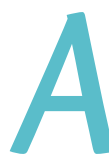

fter 2 years of unprecedented debate and coalition-building, the U.S. Congress passed a landmark Farm Bill in June 2008. By the time it was enacted, the "Food, Conservation, and Energy Act of 2008" had sparked historic levels of public interest and redirected federal funding from established channels. Among other reforms, it strengthened conservation and environmentally friendly farming practices, provided support for local farmers markets and healthy diets, advanced responsible energy production, and increased assistance for families struggling with rising food costs.

Most notably for California, the Farm Bill also created a Specialty Crops Research Initiative to be

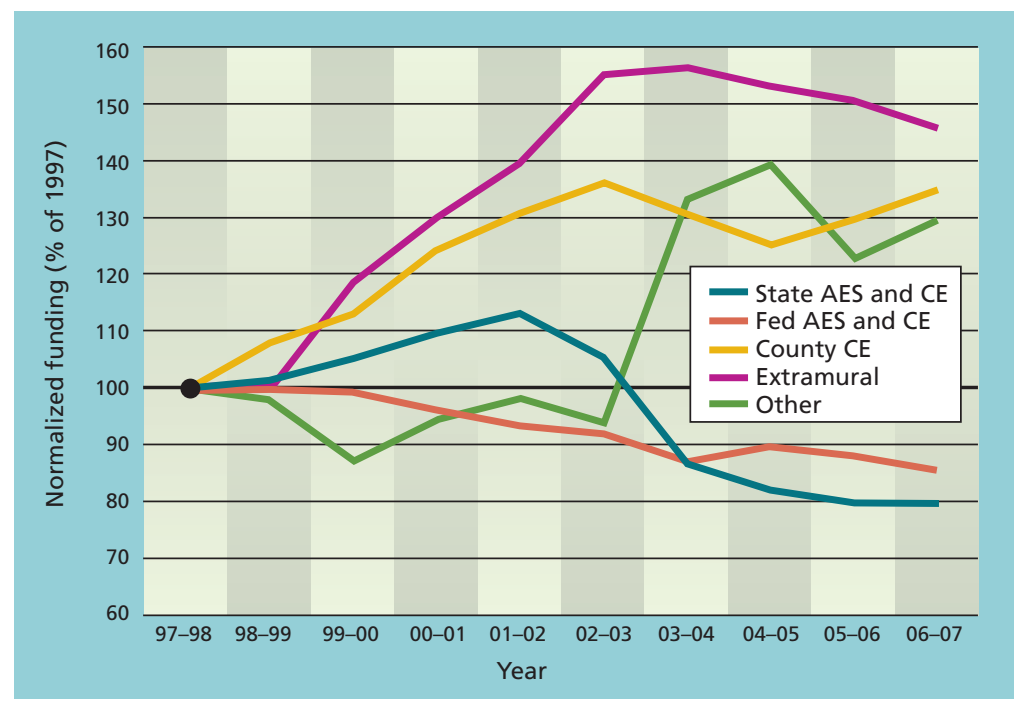

Real trends in UC Division of Agriculture and Natural Resources (ANR) funding sources, 1997-2007, normalized to 1997 funding base (represents $100 \%$ level). $\mathrm{AES}=$ Agricultural Experiment Station; $\mathrm{CE}=$ Cooperative Extension; county CE = funding from county governments; extramural = private and government contracts and grants; other = income generated by ANR. $\varangle$ Critical research often requires highly trained personnel, advanced instrumentation and updated laboratories - all requiring permanent funding support. Left, vegetative propagation of grape.

administered by a newly formed National Institute of Food and Agriculture (NIFA). For the first time, a Farm Bill recognized the importance of specialty crops to the nation's health and quality of life, and the unique role that California plays in the nation's agricultural system.

NIFA's competitive research program is good news for California. Our state, especially the University of California, traditionally fares well in obtaining competitive grants. Already, through the unified efforts of commodity groups and the research community, California agriculture is benefiting from more than $\$ 4$ million in new research funding for specialty crop needs awarded in FY 2008.

\section{Permanent funding in decline}

Although welcome, this new source of competitive grant funding does not go far enough. It does not address the need for permanent funding to sustain UC faculty and staff who generate the continuous flow of agricultural science breakthroughs and new technologies. Our history of publicly funded research and extension has been the envy of the world and has contributed substantially to California agriculture - a $\$ 37$ billion industry, producing more than 350 commodities, providing more than $50 \%$ of the nation's fresh fruit and vegetables, creating over 1 million jobs and exporting more than $\$ 10$ billion a year in products.

Unfortunately, recent California trends show declining rates of productivity growth, as noted in this issue's editorial (see page 2). Agricultural economists at UC Davis, the University of Minnesota and California Polytechnic State University, San Luis Obispo, have linked this productivity slowdown to shifts in spending and declining public investment in agricultural research and extension (see figure). Since 1990, state and federal funds supporting the UC Division of Agriculture and Natural Resources (ANR) permanent base budget declined about $20 \%$ in real dollars. Today, these permanent funds represent less than $45 \%$ of total ANR dollars, and the result has been a $24 \%$ reduction in UC Agricultural Experiment Station (AES) scientists and Cooperative Extension (CE) academics over the past 2 decades. This loss of experienced campus- and county-based scientists is even more troubling because $52 \%$ of ANR academic staff - AES researchers and CE specialists and advisors - are expected to retire within the next 10 years. If they are not replaced, the consequences will be dire.

Conversely, competitive grant funding awarded to UC researchers and programs has increased by 
$49 \%$ since 1990 and now is roughly equivalent to base permanent funding in the Division. So-called extramural funding - from competitive grants, contracts and cooperative agreements - is critical to UC's research and extension mission. For example, the Gordon and Betty Moore Foundation, the U.S. Department of Agriculture, the California Department of Water Resources, commodity boards and private growers variously supported research in this issue. However, these dollars, otherwise known as "soft money," do not provide the long-term stability and continuity needed to sustain agricultural research, development and extension programs into the future. Why is this? Because base or permanent funding from federal and state governments is critical to supporting and retaining personnel.

Over $90 \%$ of permanent dollars in the ANR budget directly fund salaries for campus- and county-based AES and CE academics and support staff. While the substantial increase in extramural grant funding confirms the excellence of UC scientists, soft money can only go so far. Scientists and technicians are needed to ensure the continuity and rigor of long-term, technical research. Human resources (scientists, specialists, advisors, research assistants) are the University's most important resource, and the loss of permanent state and federal funds (in real dollars) reduces the capacity of faculty and staff to address current and future challenges facing specialty crop growers and our natural resource base.

\section{Addressing critical needs}

Agriculture in our state is unique - California grows hundreds of crops and is the nation's sole source of nearly 20 major commodities - and critical needs arise without warning, often requiring both a rapid response to control a problem and a more sustained response to resolve it. Examples are the recent discovery of the potentially damaging citrus pest, Asian citrus psyllid, in San Diego and Imperial counties; the decline in populations of honeybees essential to pollination of many California crops; and the continuing challenge of sudden oak death (see page 10). Research addressing these challenges is highly technical, requiring stages of basic and intermediate research, as well as applied field research. The investigations require long-term commitments of teams of scientists, often across disciplines.

Does ongoing investment in research benefit consumers and the broader community? Past history and accomplishments say yes. The current upward fluctuation in food prices is a reminder that we have enjoyed a plentiful, nutritious and relatively inexpensive food supply. However,
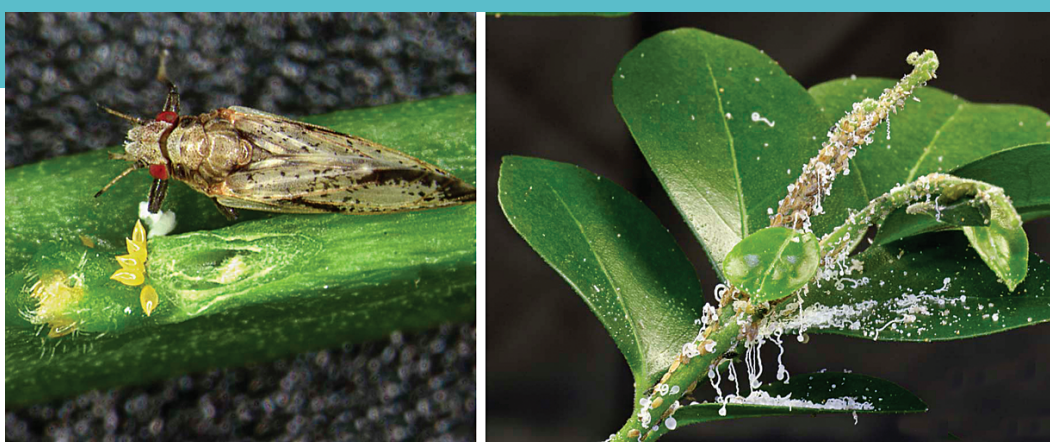

California agriculture is now called upon to address much more than just productivity and quality. We must produce safe and high-quality food while safeguarding land, air, water and wildlife.

Strong, publicly funded research, development and extension programs at UC are critical for California agriculture to remain both competitive in global markets and sustainable and environmentally responsible at home. This is an investment in the future that provides measureable returns of $\$ 10$ to $\$ 20$ for every $\$ 1$ in public funds (see page 2). Congress and the California State Legislature should be encouraged to increase public funding for agricultural research - few investments have such a high return these days.

But, public investment alone is not the answer. Agriculture, the environmental and natural resources communities and other sectors that benefit from UC research must increase their commitment to the Agricultural Experiment Station and Cooperative Extension, providing sustained funding for longer-term scientific investigations. Our industry's future, and the ability to ensure that "California grown" products will help feed the nation and the world in the future, is in the balance.
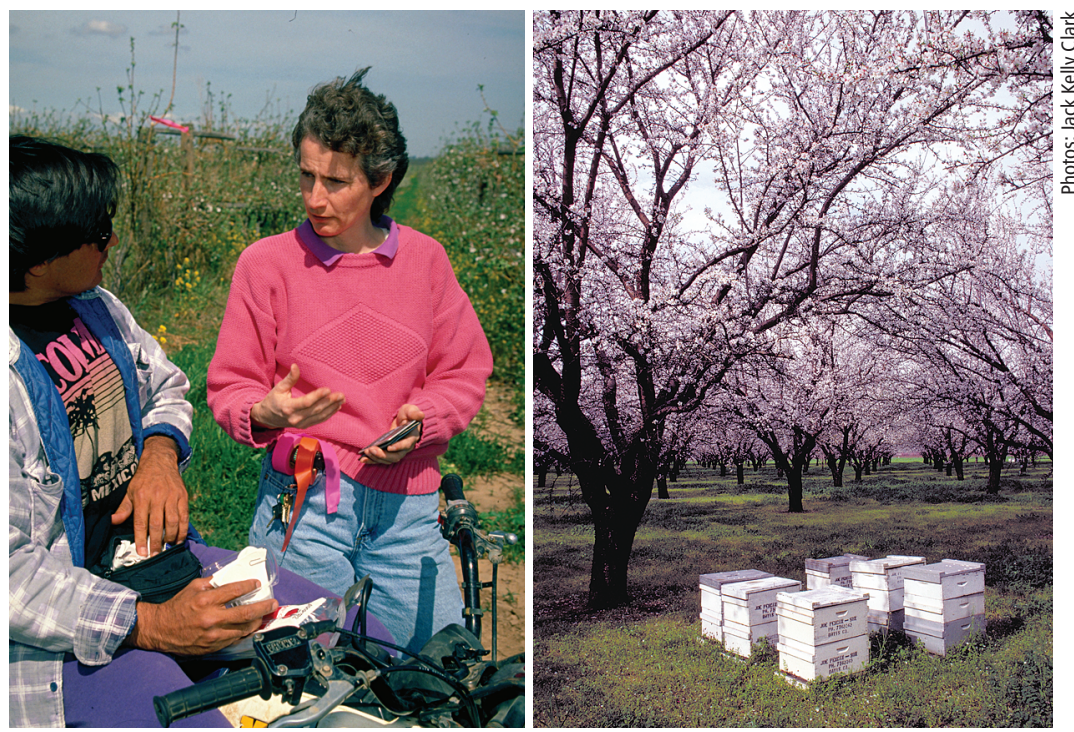

UC ANR research is often highly technical, requiring stages of basic, intermediate and applied field research. Left, farm advisor Janet Caprille explains the procedure for releasing Trichogramma wasps, which control caterpillar pests. Right, honey bee hives in an almond orchard. European honey bees, which pollinate about one-third of the world's food, are declining in population. UC scientists are investigating several possible causes, including diseases, climate change and colony collapse disorder.

\begin{abstract}
$\triangle$ Statewide unexpectedly, such as the recent discovery of, left, Asian citrus psyllid in San Diego and Imperial counties. Adult psyllids damage plants directly through feeding and are efficient vectors of the bacterium that causes citrus greening. Right infestation.
\end{abstract}

\section{.}

